\title{
Enhancement of Resistance against Oxidation with Carbon Dioxide for Formed Coke and Electrode-grade Graphite and Carbon by In- filtrating Carbon into Pores
}

\author{
Yoshihito SHIGENO ${ }^{11}$ and J. W. EVANS
}

Department of Materials Science and Mineral Engineering, University of Carlifornia, Berkely, CA, 94720, U.S.A.

1) Now Institute for Advanced Materials Processing, Tohoku University, Katahira, Aoba-ku, Sendai, Miyagi-ken, 980 Japan.

(Received on September 29, 1992; accepted in final form on March 19, 1993)

\begin{abstract}
Formed coke, electrode-grade graphite (E.G.) and electrode-grade carbon (E.C.) were modified by infiltrating carbon within the pores by use of methane cracking. The rate of oxidation with $\mathrm{CO}_{2}$ was lowered for all these samples but the amount of reduction was dependent on pore structures. Decrease in the rate for the electrode-grade carbon was very large compared to other samples. The mechanism of enhancement of resistance against oxidation was explained in terms of the pore structure changes accompanying infiltration and oxidation.
\end{abstract}

KEY WORDS: formed coke; graphite; carbon; infiltration; impregnation; pore; methane; thermal decomposition; cracking; oxidation; resistance; carbon dioxide.

\section{Introduction}

The degradation of coke in a blast furnace is considered to be mainly due to decrease in mechanical strength accompanying the oxidation: $\mathrm{C}+\mathrm{CO}_{2}=$ $2 \mathrm{CO}^{1,2)}$ Therefore, if low-grade coke which is generally sensitive to oxidation is improved by having its resistance to oxidation increased up to that of regular coke, it can be used in a blast furnace.

From this view point, modifications of low-grade coke have been tried to enahnce the resistance to oxidation. Ogawa et al. used liquid tar to impregnate pores in coke. $^{3)}$ They reported an improvement of the mechanical ambient tumbler strength and also the mechanical strength after oxidation. However, a vast amount of soot produced prevented the application to a commercial process. ${ }^{4)}$ Vandezande also reported on the infiltration of coke by use of hydrocarbons. However, he coated the outer surface of coke by deposited carbon. ${ }^{5)} \mathrm{He}$ also reported an improvement of mechanical ambient tumbler strength and also the mechanical strength after oxidation. However the effect was not so large because coke was oxidized at nearly the same rate after the outer surface layer of carbon was removed by oxidation. Therefore, these trials have not succeeded in being applied to a commercial process.

The present authors reported that the reactivity of the metallurgical coke with $\mathrm{CO}_{2}$ could be lowered by infiltrating carbon into the pores where major oxidation occurs $^{6)}$ and that the mechanical strength after oxida- tion of the infiltrated coke increased greatly. ${ }^{7,8)}$ For infiltration, methane cracking: $\mathrm{CH}_{4}=\mathrm{C}+2 \mathrm{H}_{2}$ was used. In this case, the macropores are not necessary to be impregnated because the major oxidation is considered to occur in the small pores owing to their relatively larger specific surface area than that of macropores. This is very important factor in applying the technique to a commercial process because a short time for infiltration is desirable for the economics of production. $^{8)}$

In the present paper, formed coke was infiltrated and then oxidized in the same way as described in the previous paper. ${ }^{6)}$ Formed coke is currently not exploited in a blast furnace because it has high reactivity to $\mathrm{CO}_{2}$ in general and this is considered to be the major problem for formed coke.

Electrode-grade graphite (E.G.) and electrode-grade carbon (E.C)* were also tested to consider the effect of the difference in pore structure. The changes of pore size and surface area were determined by use of a mercury porosimeter.

\section{Infiltration and Oxidation Experiment}

\subsection{Experimental Apparatus and Procedure}

The apparatus is the same as that reported previously $^{6,7)}$ and is illustrated in Fig. 1. The formed coke, E.G. and E.C. were cut into slabs $(25.4 \mathrm{~mm}$ in height, $25.4 \mathrm{~mm}$ in width and $3 \mathrm{~mm}$ in thickness). They were suspended in the uniform temperature zone $( \pm 5 \mathrm{~K})$ 


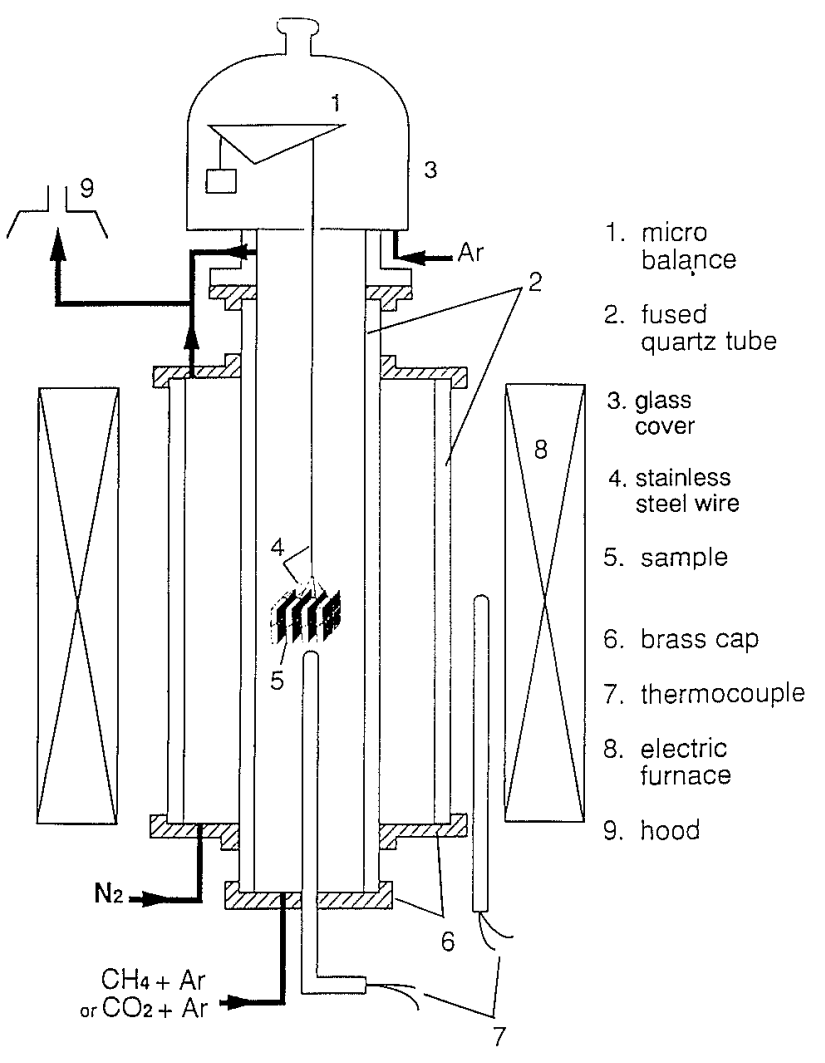

Fig. 1. Schematic diagram of experimental apparatus.

of the furnace with a stainless steel wire. Four plates were infiltrated at the same time then two of them were oxidized and remaining two plates were used for an analysis of pore size and surface area distributions by use of a mercury porosimeter. The infiltration and oxidation rates were determined by monitoring the weight continuously.

The reaction tube ( $40 \mathrm{~mm}$ in inner diameter) is surrounded by another lager coaxial tube $(57 \mathrm{~mm}$ in inner diameter). They were made of transparent fused silica. Between the outer and inner tube, cooling gas $\left(\mathrm{N}_{2}\right)$ flowed at $6.7 \times 10^{-5} \mathrm{~m}^{-3} \mathrm{~s}^{-1}\left(4 l \mathrm{~min}^{-1}\right)$ to keep the inner tube cool and thereby to prevent carbon depositing on the inner surface of the reaction tube. Therefore, the sample was heated by radiation from the electric furnace.

The reaction gas for infiltration was a mixture of methane $(24 \%)$ and argon which was introduced from the bottom of the reaction tube. The flow rate of the gas mixture was $9.7 \times 10^{-6} \mathrm{~m}^{-3} \mathrm{~s}^{-1}\left(0.58 l \mathrm{~min}^{-1}\right)$. The unreacted methane and cooling gas were merged to dilute the methane concentration to below the flammable limit for venting into the air through a hood. A continuous argon purge protected the balance chamber from unwanted deposition. The temperature was measured by a type $\mathrm{K}$ thermocouple inserted just underneath the sample. The temperature of the furnace was controlled by a second thermocouple set outside the reaction tube, adjacent to the heating element.

Oxidation followed the infiltration experiment with changes in only a few experimental conditions; the reaction gas was a mixture of $\mathrm{Ar}$ and $\mathrm{CO}_{2}(10 \%)$, the gas flow rate was $5 \times 10^{-5} \mathrm{~m}^{-3} \mathrm{~s}^{-1}\left(3 / \mathrm{min}^{-1}\right)$, temperature,was $1.223 \mathrm{~K}$ and no cooling gas was used.

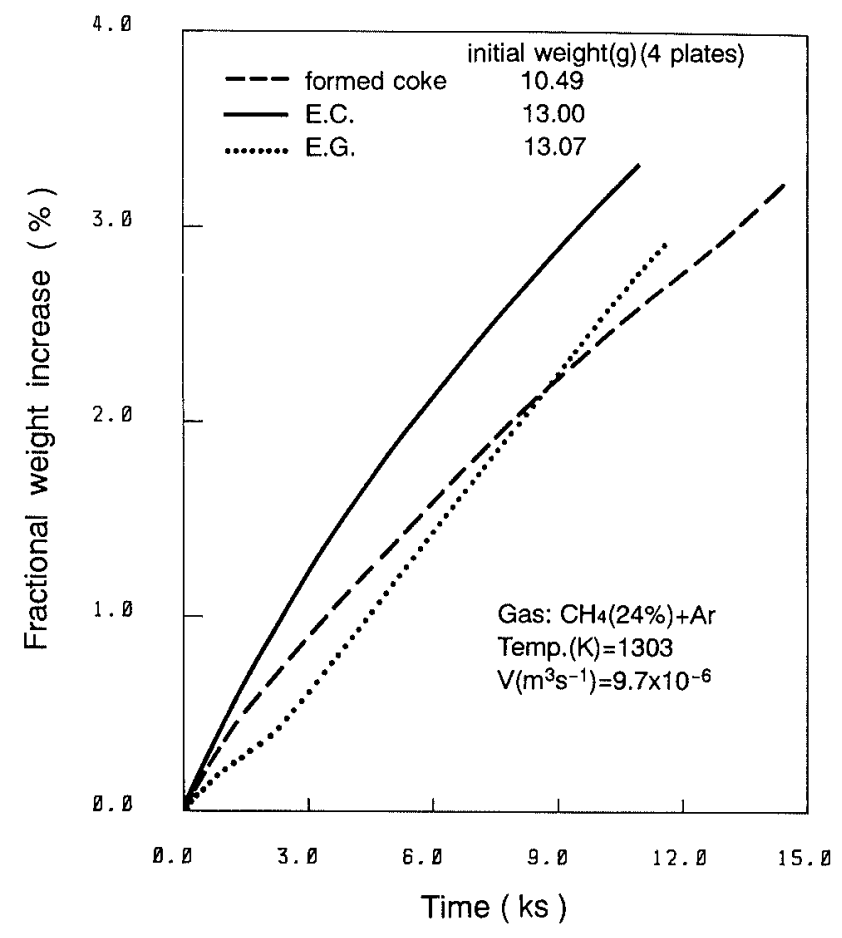

Fig. 2. Fractional weight increase with time for formed coke, electrode-grade graphite (E.G.) and electrode-grade carbon (E.C.).

\section{Experimental Results}

\subsection{Weight Increase with Time due to Infiltration}

In Fig. 2, the fractional weight increase during infiltration is shown for formed coke, E.G. and E.C. The fractional weight increased monotonically with time but the mode of increase is slightly different among the samples. The reason of the different mode of each sample is discussed in Sec. 4.

As carbon deposited on the inner surface of the pore, no deposited carbon was observed on the outer surface of any sample with naked eyes.

\subsection{Comparison of Oxidation Rate between Original and Infiltrated Samples}

Figures 3, 4 and 5 show the comparison of oxidation rates for original and infiltrated samples for formed coke, E.G. and E.C., respectively.

Fractional weight decrease of the infiltrated formed coke was $73 \%$ of that for the original formed coke $7.2 \mathrm{ks}$ after oxidation started. The oxidation rate was constant for the original formed coke $\left(6.0 \times 10^{-4}\left(\% \mathrm{~s}^{-1}\right)\right)$ but for the infiltrated formed coke, it gradually decreased: (initial rate $=4.8 \times 10^{-4}\left(\% \mathrm{~s} \mathrm{~s}^{-1}\right)$, final rate $=3.12 \times 10^{-4}$ $\left(\% \mathrm{~s}^{-1}\right)$. The final oxidation rate of the infiltrated formed coke was by about $50 \%$ of that of the original formed coke.

In the case of E.G., the fractional weight decrease of the infiltrated formed coke was $81 \%$ of the that of original E.G. $7.2 \mathrm{ks}$ after oxidation started. Differing from the formed coke, the oxidation rate decreased with time for the original E.G. as well (initial rate= $6.24 \times 10^{-4}\left(\% \mathrm{~s}^{-1}\right)$, final rate $=3.48 \times 10^{-4}\left(\% \mathrm{~s}^{-1}\right)$. The decrease in the oxidation rate was somewhat smaller for the infiltrated E.G. (initial rate $=5.04 \times$ 


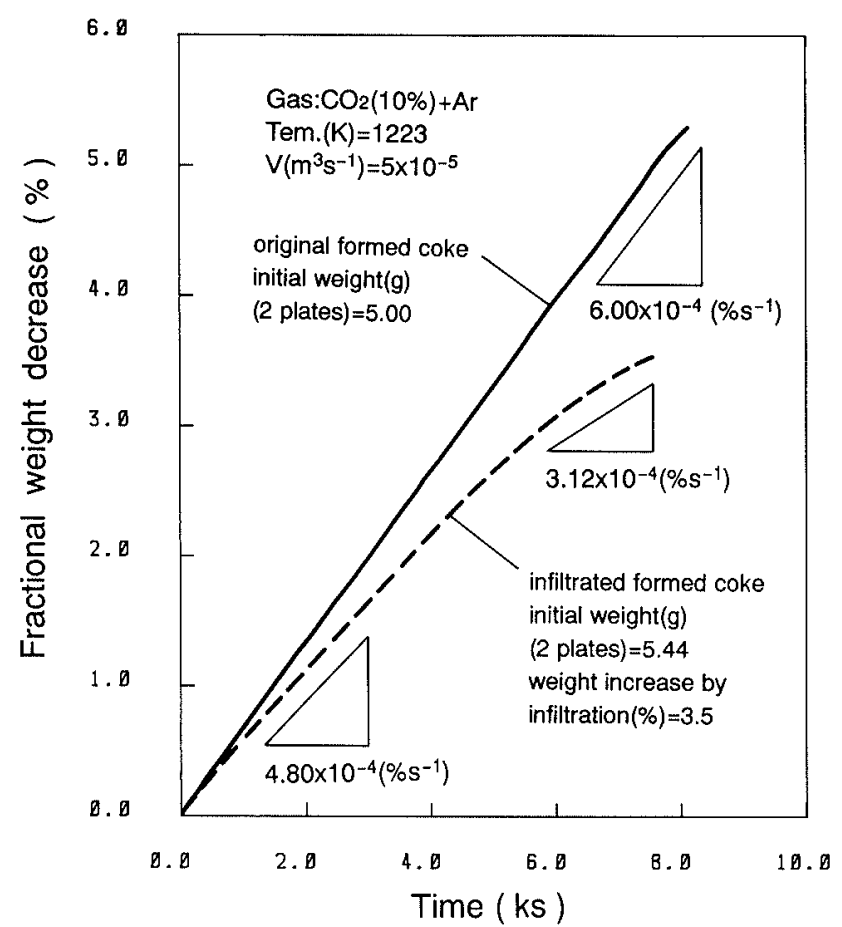

Fig. 3. Comparison of oxidation rates between original and infiltrated formed coke.

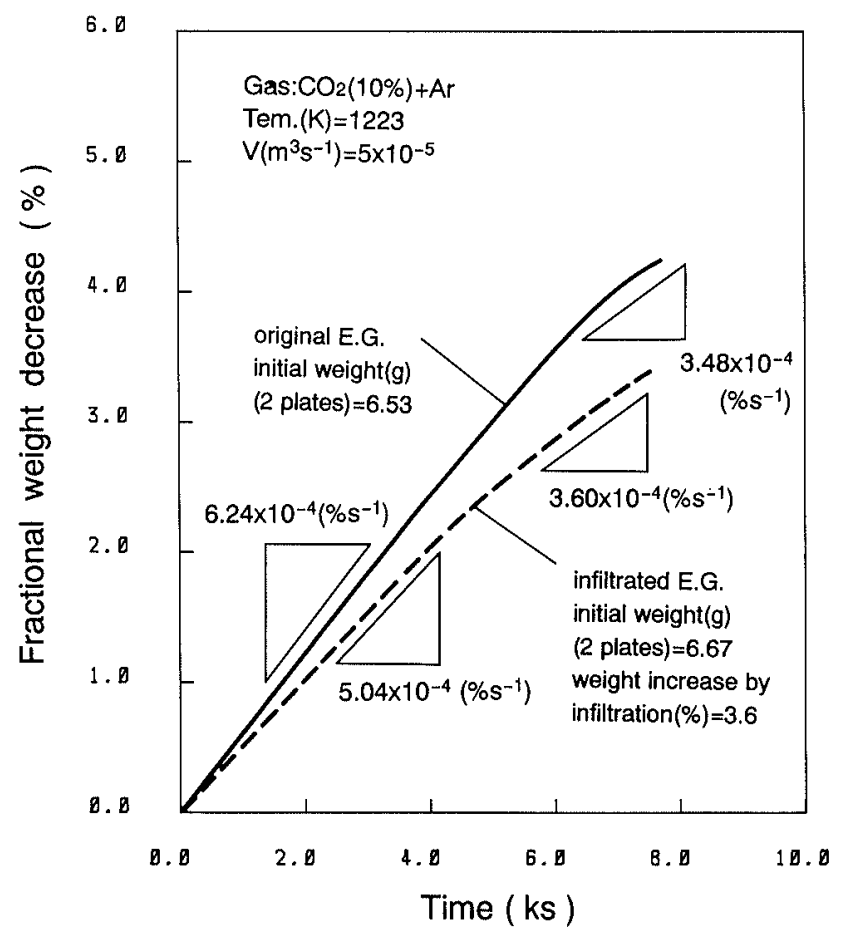

Fig. 4. Comparison of oxidation rates between original, and infiltrated electrode-grade graphite (E.G.).

$10^{-4}\left(\% \mathrm{~s}^{-1}\right)$, final rate $\left.\left.=3.60 \times 10^{-4}\left(\% \mathrm{~s}^{-1}\right)\right)\right)$. The final rates for both samples were almost the same. The decrease in the oxidation rate for the original E.G. is also seen in the result by Turkdogan et al. ${ }^{9)}$

In the case of E.C., the fractional weight decrease of the infiltrated E.C. was $49 \%$ of that of the original E.C. $6.4 \mathrm{ks}$ after oxidation started. The rate of oxidation for the original E.C. decreased finally to $53 \%$ of the initial value (initial rate $=1.13 \times 10^{-3}\left(\% \mathrm{~s}^{-1}\right)$, final rate $=$

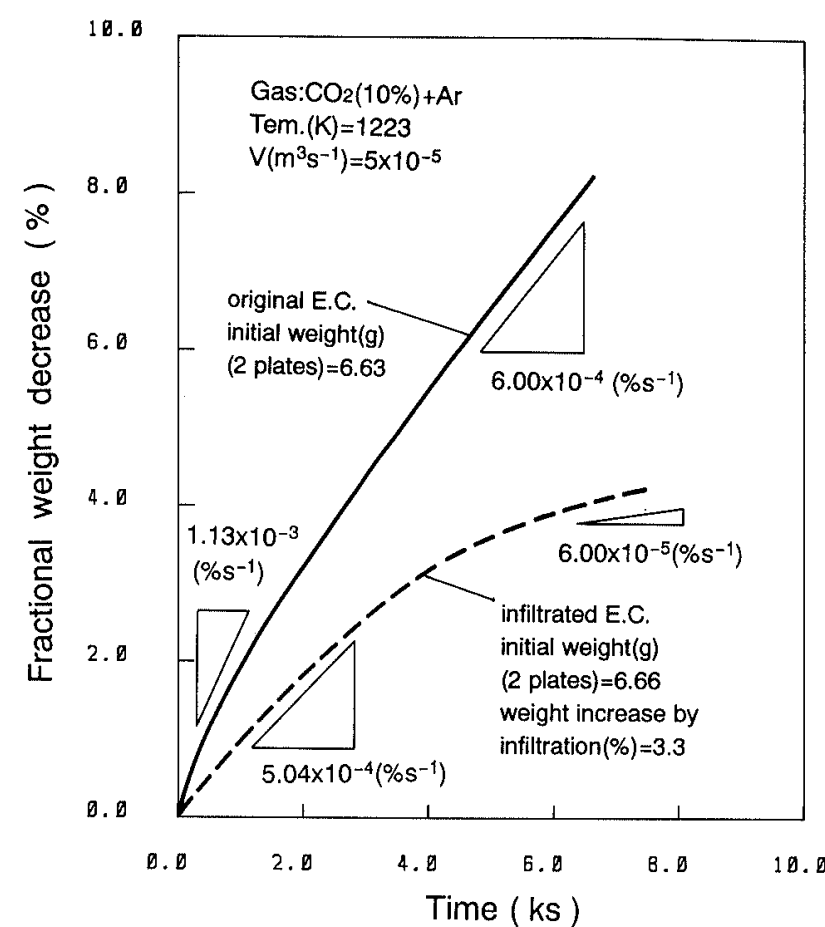

Fig. 5. Comparison of oxidation rates between original and infiltrated electrode-grade carbon (E.C.).

$\left.6.00 \times 10^{-4}\left(\% \mathrm{~s}^{-1}\right)\right)$. This behavior was like to that of E.G. but the decrease for the infiltrated E.C. was much larger than for other samples. The rate decreased finally to $11.9 \%$ of the initial rate (initial rate $=5.04 \times 10^{-4}$ $\left(\% \mathrm{~s}^{-1}\right)$, final rate $\left.=6.00 \times 10^{-5}\left(\% \mathrm{~s}^{-1}\right)\right)$ and was likely to approach 0 asymptotically.

\subsection{Pore Structure Change Accompanying Infiltration and Oxidation}

Figures 6, 7 and 8 show the changes of cumulative volume of 1) original 2) oxidized 3) infiltrated 4) infiltrated and then oxidized samples. The samples are formed coke, E.G. and E.C., respectively.

For the formed coke, the pore structure changed in the similar manner to the metallurgical coke described in the previous paper. ${ }^{6,7)}$ In oxidation, the relatively large pores of original formed coke in the range from 1 to $5 \mu \mathrm{m}$ were enlarged as shown by the steeper slope $(-d V / d(\log r))$ for the oxidized original formed coke than for the original one. In infiltration, there were relatively large pores and also the small pores in the range from 30 to $300 \mathrm{~nm}$ were impregnated as shown by the plateau in this range. When infiltrated formed coke was oxidized, the relatively large pores were enlarged remarkably while the small pores were enlarged slightly.

The pore size distribution of E.G. is bimodal; in both range of 1 to $10 \mu \mathrm{m}$ and 10 to $100 \mathrm{~nm}$, a pore-size distribution peak is existing. When oxidized, the larger pores (macropores) were not enlarged but the pores in the range of 30 to $300 \mathrm{~nm}$ were enlarged. This is seen from the fact that the slope of oxidized E.G. became steeper than that of original E.G. When infiltrated, only the macropores decreased their size. When the infiltrated sample was oxidized, the macropores were enlarged but the small pores did not change their size. 


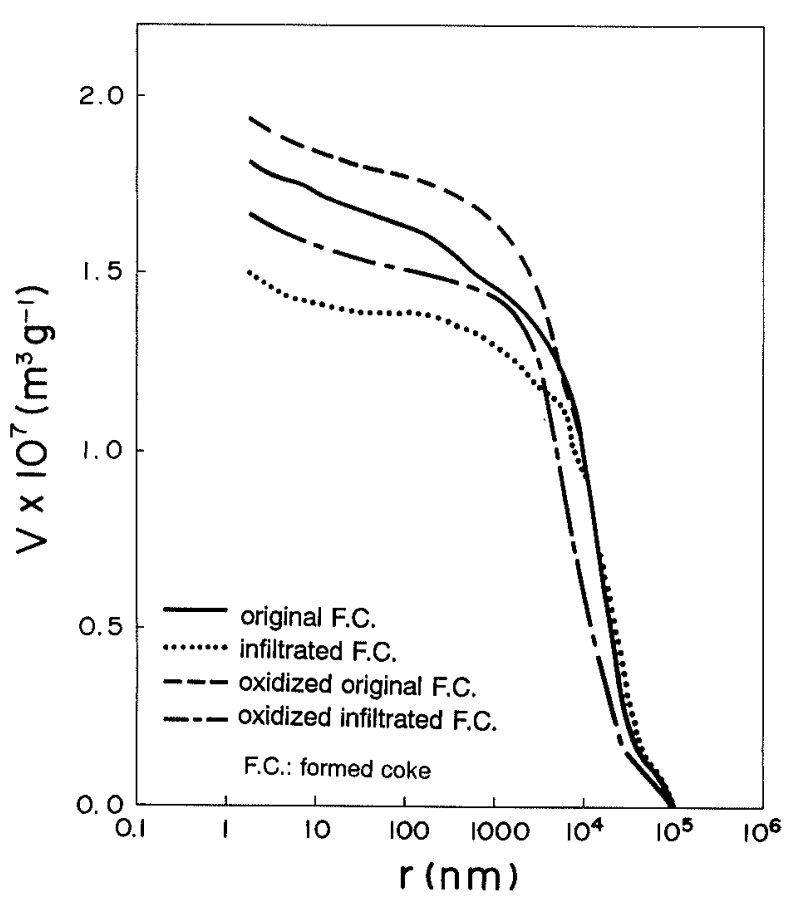

Fig. 6. Charges in cumulative pore volume of original, infiltrated and oxidized (original and infiltrated) formed coke. The infiltrated and oxidized samples were one of the plates after infiltration and oxidation shown in Figs. 2 and 3, respectively.

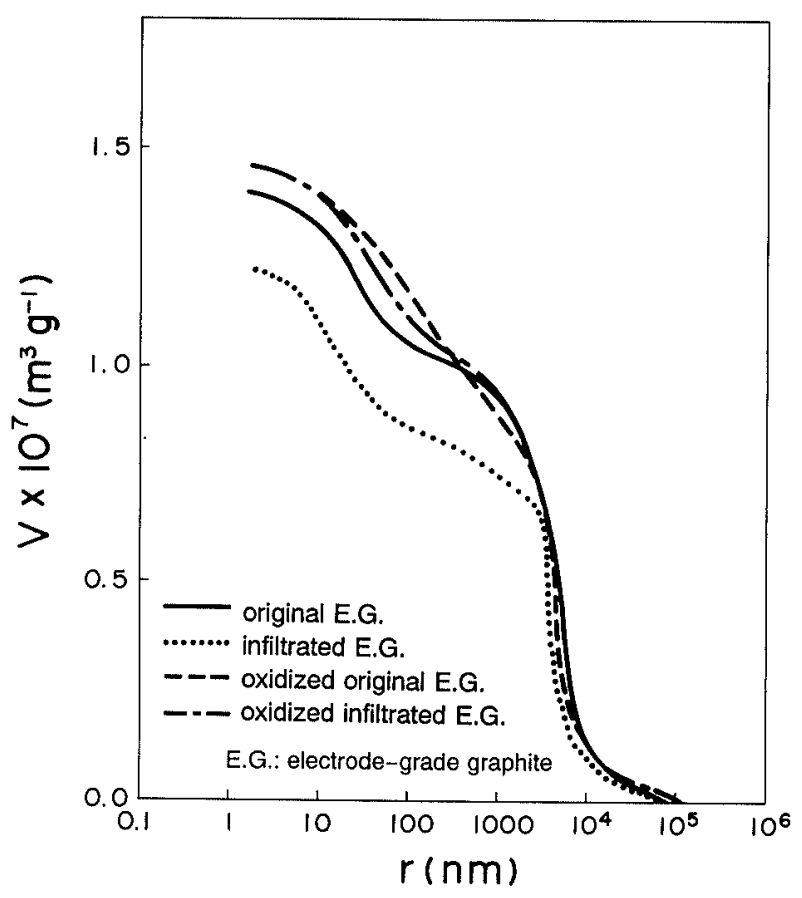

Fig. 7. Changes in cumulative pore volume of original, infiltrated and oxidized (original and infiltrated) electrode-grade graphite. The infiltrated and oxidized samples were one of the plates after infiltration and oxidation shown in Figs. 2 and 4, respectively.

The pore size distribution is different between E.G. and E.C. This difference reflects the change in pore structure in the graphitization process because the difference between E.G. and E.C. is solely graphitizing temperature. For E.C., the larger pores (macropore) are distributed mainly in the range of $100 \mathrm{~nm}$ to $1 \mu \mathrm{m}$ but

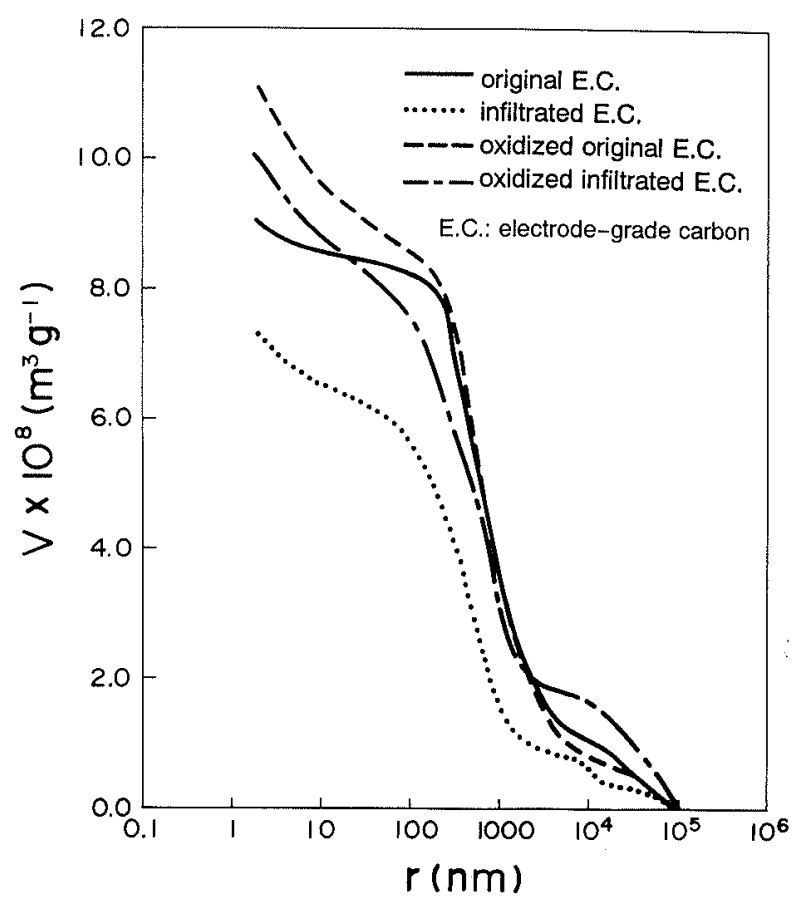

Fig. 8. Changes in cumulative pore volume of original, infiltrated and oxidized (original and once infiltrated) electrode-grade carbon. The infiltrated and oxidized samples were one of the plates after infiltration and oxidation shown in Figs. 2 and 5, respectively.

the pore volume between 10 and $100 \mathrm{~nm}$ is very small. The remaining pores are micropore under $6 \mathrm{~nm}$. When oxidized, the pores under $200 \mathrm{~nm}$ were enlarged as shown by the steep slope for the oxidized original E.C. compared to that of the original E.C. But the large pore did not change. This lack of change of the large pores is the characteristic feature of E.C. When infiltrated, the pores in all ranges were infiltrated. The steeper slope under $100 \mathrm{~nm}$ for the infiltrated E.C. than that for the original E.C. is attributed to formation of "bottle-neck type" pores. ${ }^{6)}$ With pore diameter decreasing and pore length increasing, the gas diffusion in pores becomes the rate limiting step. This leads to the concentration gradient of gas: the relatively higher concentration at the entrance than that in the inner part of the pore. As the thickness of deposited layer of carbon is proportional to the reaction gas concentration, the pore impregnated by carbon forms the "bottle neck" as is illustrated in f) and j) in Fig. 12. These pores sometimes results in the raise in the pore volume at smaller size than the actual one because the pore diameter is represented by that of the mouth of the bottle neck. ${ }^{10)}$

When the infiltrated E.C. was oxidized, mainly the pores larger than $1000 \mathrm{~nm}$ were enlarged.

\subsection{Change in Surface Area by Infiltration and Oxida- tion}

Figures 9, 10 and 11 show the changes of surface area of 1) original 2) oxidized 3) infiltrated 4) infiltrated and then oxidized samples. They are corresponding to formed coke, E.G. and E.C., respectively.

For the formed coke and E.G, the significant change in surface area due to infiltration and oxidation is 


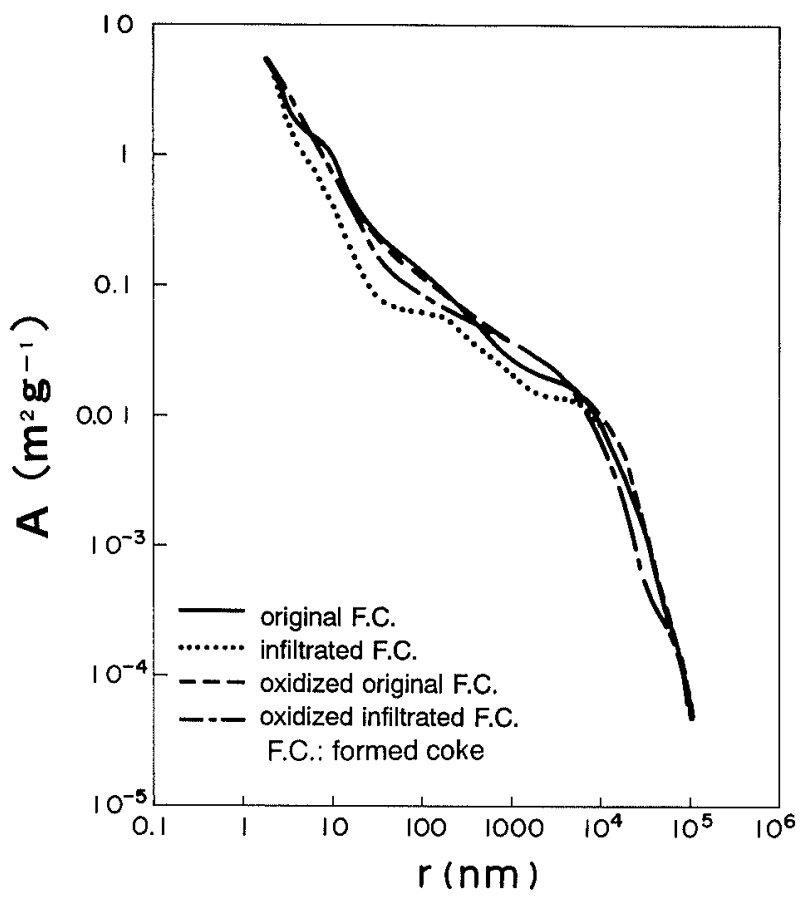

Fig. 9. Changes in cumulative surface area of original, infiltrated and oxidized (original and infiltrated) formed coke. The infiltrated and oxidized samples were one of the plates after infiltration and oxidation shown in Figs. 2 and 3, respectively.

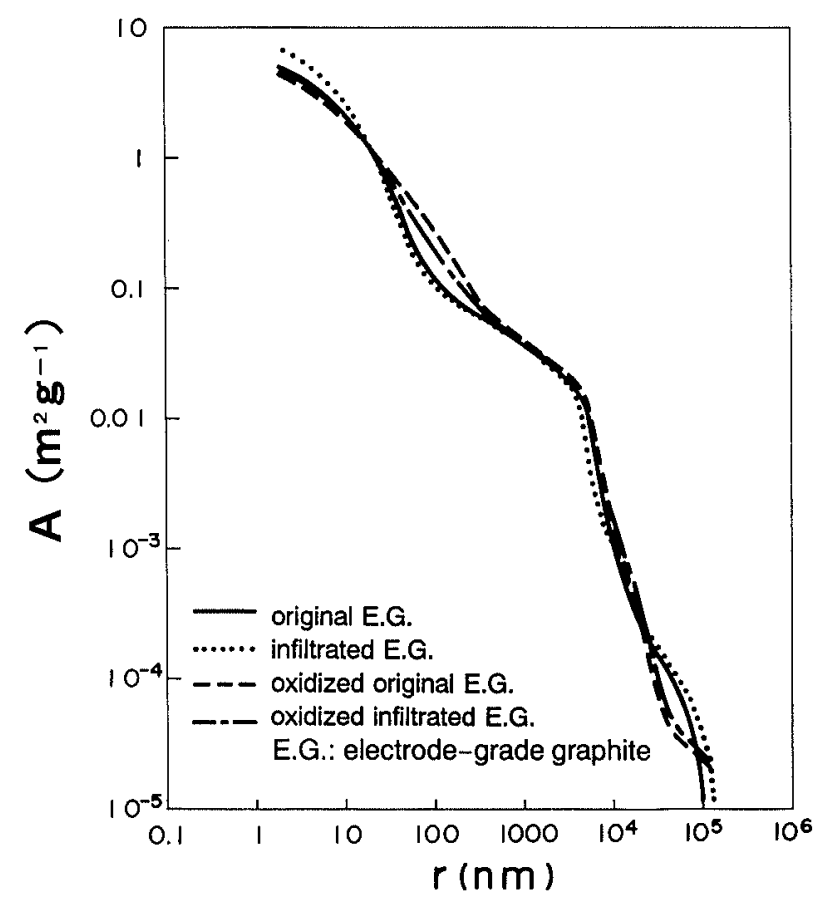

Fig. 10. Changes in cumulative surface area of original, infiltrated and oxidized (original and infiltrated) electrode-grade graphite. The infiltrated and oxidized samples were one of the plates after infiltration and oxidation shown in Figs. 2 and 4, respectively.

restricted to the small pores (from about 30 to $300 \mathrm{~nm}$ ). Change in surface area of macropores is negligibly small. This is also observed in metallurgical coke reported previously. ${ }^{6,7)}$ Therefore, the small pores in this range are considered to be dominant in determining the reaction rates.

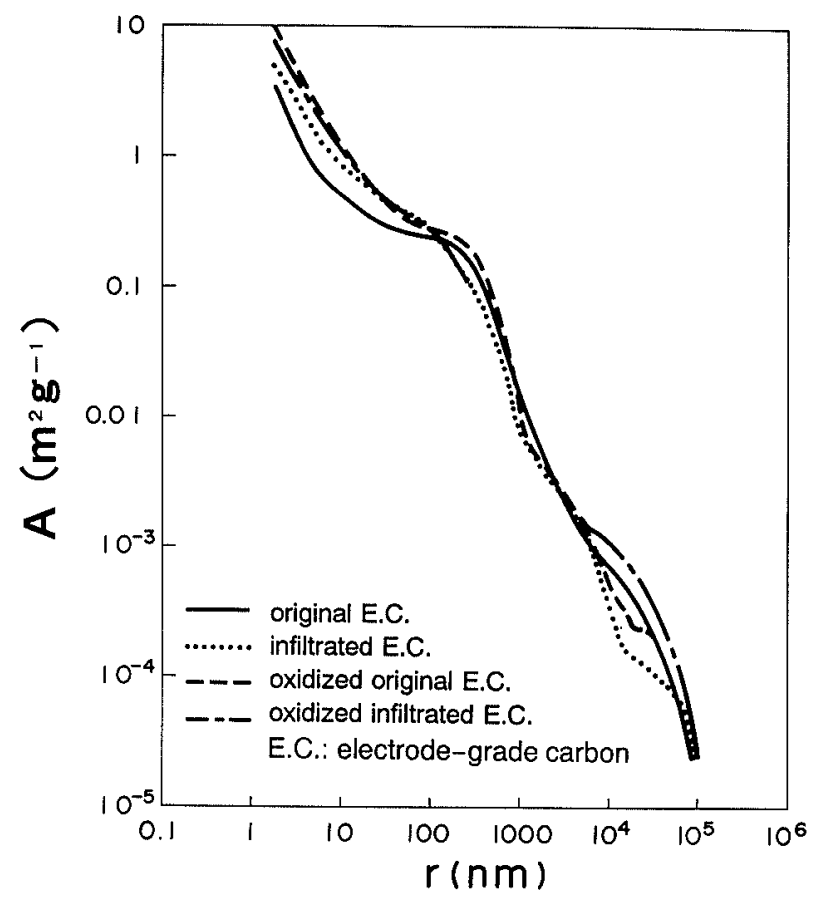

Fig. 11. Changes in cumulative surface area of original, infiltrated and oxidized (original and infiltrated) electrode-grade carbon. The infiltrated and oxidized smaples were one of the plates after infiltration and oxidation shown in Figs. 2 and 5, respectively.

However, for E.C., the total area under $100 \mathrm{~nm}$ of the infiltrated sample was larger than the original one. This is also attributed to overestimation of surface area for "bottle-neck type" pore. ${ }^{10)}$

Oxidation of original E.C. enlarged the total surface area by three times in contrast with substantially no change for the formed coke and E.G.

\section{Discussion}

In Fig. 12, the changes during formation of the deposited carbon layer during infiltration and during subsequent oxidation are illustrated. The formed coke and E.G. have pore-size distribution peaks of macropores in the range of pore radius between 1 and $10 \mu \mathrm{m}$, while E.C. has macropores between $100 \mathrm{~nm}$ and $1 \mu \mathrm{m}$ as shown in Figs. 6, 7 and 8. They are drawn as the main large pore in $\mathrm{a}, \mathrm{b}$ and $\mathrm{c}$ in Fig. 12. The pore-size distributions of smaller pores are different between the samples. The smaller pores distribute uniformly under $1 \mu \mathrm{m}$ for formed coke, between 10 and $100 \mathrm{~nm}$ for E.G. and under $6 \mathrm{~nm}$ for E.C. (the volume of pores between 6 and $100 \mathrm{~nm}$ is very small). Those smaller pores are drawn as branches from the macropore.

The oxidized pores of original sample are not illustrated in Fig. 12 to avoid complicating the figure. As described in Sec. 3.3, during oxidation, the macropores of the formed coke were enlarged without change in the size of the smaller pores. In contrast, for E.G. and E.C., the macropores did not change but small pores formed in the range of 30 to $300 \mathrm{~nm}$ for E.G. and under $100 \mathrm{~nm}$ for E.C. The difference in oxidation mode of the original samples shown in Figs. 3, 4 and 5 appears to be a reflection of the difference of change in pore structures 


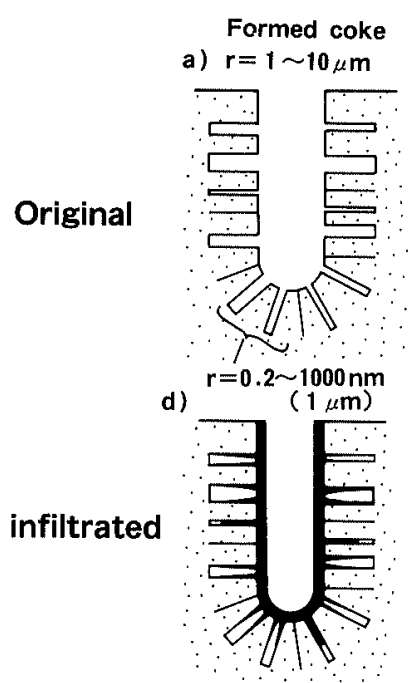

g)

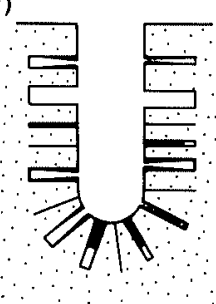

E.G.

b) $\mathrm{r}=1 \sim 10 \mu \mathrm{m}$

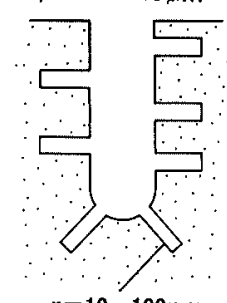

e)
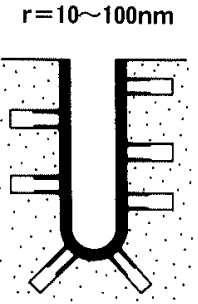

h)

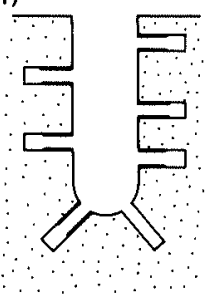

E.C.

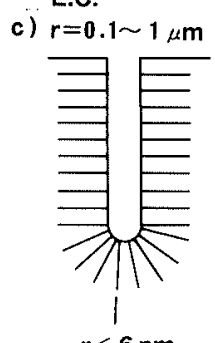

f)

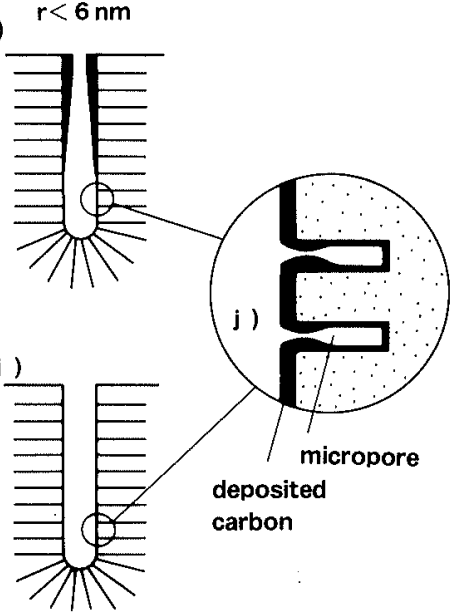

Fig. 12.

Schematic illustration of pore structure changes of formed coke, electrode-grade graphite (E.G.) and electrode-grade carbon (E.C.) during infiltration and oxidation following infiltration. described above. Generally, when the small pores (or the micropores) are enlarged by oxidation, the oxidation rate is large at the beginning because of the large micropore surface area but the rate gradually decreases as these small pores coalesce and larger pores are produced. This is for the case of E.G. and E.C.

On the other hand, when the large pores are oxidized in the case of F.C., the oxidation rate is constant due to little change in specific surface area as shown in Fig. 9. Because the coalescence of large pore does not occur until the higher fractional weight loss than that for E.C. and E.G.; for coalescence of lager pores, a larger amount of carbon comprising walls between pores should be exhausted.

During infiltration, the small pores and the macropores $(r=1$ to $10 \mu \mathrm{m})$ of formed coke were impregnated; in particular, the pores in the range of 30 to $300 \mathrm{~nm}$ in raidus decreased their size as seen from the plateaus of cumulative volume and surface area curves for the infiltrated formed coke shown in Figs. 6 and 9. In the case of E.G., the infiltration mode is very unusual; the macropores decreased in size (as with the formed coke) but the pore-size distributions under $1 \mu \mathrm{m}$ did not change as seen from the curve of the cumulative volume of the infiltrated E.G. that was shifted lower with a very little change in the slope. This means very little infiltration of carbon in the small pores as illustrated in Fig. 12e). In the case of E.C., the macropore was impregnated forming "bottle-neck type" pore as illustrated in $\mathrm{f})$. This is seen from the steeper slope $(-d V / d(\log r))$ for the infiltrated E.C. than that of the original E.C. in the range from 10 to $300 \mathrm{~nm}$. Increase in slope is also seen under $6 \mathrm{~nm}$. This is also because of the formation of the "bottle-neck type" pore in the micropores illustrated in Fig. 12j). The different shapes of the curves for the fractional weight increase with time in Fig. 2 , can be explained in terms of different mode of the infiltration as follows. The macropores in formed coke and E.G. are larger than that of E.C., therefore, the deposited layer with uniform thickness formed for the former samples due to the larger radius of pore, ${ }^{7)}$ leading to an almsot linear fractional weight increase with time. However, in the case of E.C., as the size of macropore is smaller than that of formed coke and E.G., the deposited carbon layer will hinder further entering of methane as shown in Fig. 12f). Therefore, the infiltration rate decreased gradually with increasing time.

When the once infiltrated formed coke was oxidized, the deposited carbon layer was oxidized at the beginning and therefore the macropores increased their size. As the deposited carbon layer remained in the small pores as shown in Fig. 12g), the oxidation rate was decreased from that of original formed coke as shown in Fig. 3. In the case of E.G., the deposited carbon in the macropore was also oxidized. The amount of deposited carbon in the small pores was negligibly small as described previously. This is also seen by a small difference in pore volume between the oxidized original E.G. and oxidized infiltrated E.G. in Fig. 7. The deposited carbon in the macropore decreased the oxidation rate by lowering the $\mathrm{CO}_{2}$ intrustion rate. However, the oxidation rates of original E.G. and infiltrated E.G. after $6 \mathrm{ks}$ became almost the same as shown in Fig. 4 because of no effect of the deposited carbon in the small pores. In the case of E.C., the deposited carbon in the macropores was oxidized but that in the micropores prevented $\mathrm{CO}_{2}$ from intruding. As the dominant ratio of the surface area of the micropores to the total area is larger for 
E.C. than formed coke and E.G., as shown in Figs. 9, 10 and 11 , the oxidation rate decreased extremely for E.C.

\section{Conclusion}

In order to modify the formed coke so as to have the higher oxidation resistance, carbon was infiltrated into pores using methane cracking. Impregnation of small pore or micropore is very important because oxidation occurs mainly in these pores where the specific surface area is far larger than that of macropores. In the previous paper, ${ }^{6}$ decrease in oxidation rate for the infiltrated metallurgical coke and an extreme increase in CSR (Coke Strength after $\mathrm{CO}_{2}$ Reaction) of infiltrated metallurgical coke ${ }^{7,8)}$ was shown.

As the formed coke has not been employed in a blast furnace and one of the reasons of it is the high reactivity to $\mathrm{CO}_{2}$ for ordinary formed coke, we aimed at modifying it to have high resistance to oxidation by infiltrating carbon using methane cracking. In the present paper, as the main objective is to study how the enhancement of the resistance to oxidation is depending on the pore structures, carbonaceous materials having different pore structures: electrode-grade graphite (E.G.) and electrode-grade carbon (E.C.) were also used. The effect of infiltration was apparent for all these samples but the degree of decrease in oxidation was dependent on the pore structures. The results are summarized as follows:

(1) The oxidation rate of formed coke was lowered by infiltration and the rate decreased with increasing time. It became half of that of original formed coke $6 \mathrm{ks}$ after oxidation started. This reduction is considered to be caused as follows.

The infiltration occurred in both macropores $(r=$ $1-10 \mu \mathrm{m})$ and small pores $(r<1 \mu \mathrm{m})$. At the beginning of oxidation, the deposited carbon in the macropores lowered the oxidation rate until it was exhausted. Then, because the deposited carbon remained in the small pores and thereby prevented carbon dioxide intruding into these small pores, the oxidation rate decreased with time and therefore it became lower than that of the original sample.

(2) The oxidation rate of infiltrated electrode-grade graphite (E.G.) was reduced from that of the original E.G. Unlike the case of formed coke, the rate of original E.G. also decreased with time, perhaps due to decrease in surface area by coalesence of small pores. Both rates for original and infiltrated samples finally became equivalent. This is explained as follows. In the case of E.G., mainly the macropores $(r=1-10 \mu \mathrm{m})$ were impregnated; impregnation of small pores $(r=10-100 \mathrm{~nm})$ was slight. In oxidation of infiltrated E.G., as the deposited carbon in the macropore was oxidized and then small pores participated in oxidation, the oxidation rate decreased a little, resulting in the same rates for original and infiltrated samples.

(3) The rate of the infiltrated E.C. decreased extremely with time compared to the decrease in that for the original E.C. This is attributed to the characteristic pore structures: the pores are comprised of macropores ( $r=0.1-1 \mu \mathrm{m}$ ) which are smaller than those of formed coke and E.G., and the micropores $(r<6 \mathrm{~nm})$. Carbon deposited over the surface of both pores by infiltration. In oxidizing this sample, oxidation started from the deposited carbon in the former pore. However, as the micropore having very large surface area was not oxidized due to impregnation, the oxidation rate decreased extremely.

\section{Acknowledgement}

The authors thank to Nippon Steel Corp. for providing formed coke.

\section{Nomenclature}

$r:$ radius of pore $(\mathrm{m})$

$V$ : cumulative pore volume per unit sample weight $\left(\mathrm{m}^{2} \mathrm{~g}^{-1}\right)$

$W: \quad$ weight $(\mathrm{g})$

\section{REFERENCES}

1) Y. Iwanaga: ISIJ Int., 31, (1991), 32.

2) Y. Hara and M. Tsuchiya: Tetsu-to-Hagané, 66 (1980), 1810

3) M. Ogawa, M. Miyawaki and T. Tsuyuguchi: Proc. 113th ISIJ (Iron and Steel Institute of Japan) Meeting, ISIJ, Tokyo, (1987), S62.

4) K. Nishioka: Private communication, Sumitomo Metal Industries Ltd., Ibaraki, Japan, (1988).

5) P. A. Vandezande: Proc. of 16th Biennial Conf. on Carbon, American Carbon Society, San Diego, (1983), 611.

6) Y. Shigeno and J. W. Evans: Metall. Trans. B, 23B (1992), 429.

7) Y. Shigeno and J. W. Evans: submitted to Metall. Trans. $B$.

8) Y. Shigeno and J. W. Evans: USA patent application.

9) E. T. Turkdogan and J. V. Vinters: Carbon, 7 (1969), 101.

10) F. A. L Dullien: Porous Media Fluid Transport and Pore Structure Academic Press, New York, (1979), 98. 